\title{
Simultaneous thermodynamic simulation of CNG filling process
}

\author{
Mahdi Deymi-Dashtebayaz ${ }^{1^{*}}$, Mahmood Farzaneh-Gord ${ }^{2}$, Hamid Reza Rahbari ${ }^{3}$ \\ ${ }^{1}$ Islamic Azad University, Department of Mechanical Engineering, Shahrood Branch, Shahrood, Iran \\ ${ }^{2}$ Department of Mechanical Engineering, Islamic Azad University, Shahrood Branch, Shahrood, Iran \\ ${ }^{3}$ Department of Mechanical Engineering, Islamic Azad University, Damghan Branch, Damghan, Iran \\ "Corresponding authors: e-mail: meh_deimi@yahoo.com
}

\begin{abstract}
In CNG station, the fuel is usually stored in the cascade storage bank to utilize the station more efficiently. The cascade storage bank is generally divided into three reservoirs, commonly termed low, medium and high-pressure storage bank. The pressures within these reservoirs have huge effects on the performance of the stations. In the current study, a theoretical simulation based on mass balance and thermodynamic laws has been developed to study the dynamic fast filling process of vehicle's (NGV) cylinder from the cascade storage bank. The dynamic change of the parameters within the storage bank is also considered. Natural gas is assumed to contain only its major component, methane, and so thermodynamic properties table has been employed for finding the thermodynamics properties. Also the system is assumed as a lumped adiabatic system. The results show that the initial pressure of the cascade storage bank has a big effect on the storage bank volumes for bringing up the NGV cylinder to its target pressure (200 bar). The results also showed that ambient temperature has effect on the refueling process, chiefly the final NGV cylinder and the cascade storage bank conditions.
\end{abstract}

Keywords: compressed natural gas, cascade storage bank, fast filling process, thermodynamic analysis, entropy.

\section{INTRODUCTION}

Compressed natural gas $(\mathrm{CNG})$ is considered one of the most promising fuel alternatives for vehicles because it is a relatively clean-burning fuel compared with gasoline ${ }^{1}$. CNG as fuel is used in different vehicles that include: passenger cars, heavy-duty trucks, garbage trucks and buses. Especially for urban vehicles, natural gas is an environmentally friendly fuel ${ }^{2}$. Using of natural gas vehicles (NGVs) began in Italy in the mid-1930s. In particular, after the energy crisis in 1970, the NGVs were rapidly developed by the governments of the developed countries and the developing ones. In Iran the numbers of NGVs and CNG stations have been estimated to be around 3 million vehicles and 2000 fast refuelling stations at the end of $2012^{3}$ and are growing rapidly.

The natural gas vehicles (NGV) usually receive natural gas from high pressure storage bank at the refuelling stations during filling. The NGV cylinders encountered a rise in the in-cylinder temperature during the filling due to complex compression and mixing processes. This temperature rise reduces the density of the gas in the cylinder, resulting in an under-filled cylinder, relative to its rated specification. If this temperature rise is not compensated for in the fuelling station dispenser, by transiently over-pressurizing the cylinder, the vehicle user will experience a reduced driving range.

The capacity of NGV cylinder is a critical subject to the wide outspread marketing of these alternate fuelled vehicles. CNG is dispensed to a NGV through a process known as the fast fill process, since it is completed in less than five minutes. Under-filling of NGV cylinders could befall at the fuelling stations, at ambient temperatures greater than $30^{\circ} \mathrm{C}$. The resulting reduced driving range of the vehicle is an important drawback which the gas industry is trying to dominate, without resorting to unnecessarily high fuelling station pressures, or by applying extensive over-pressurization of the NGV cylinder during the fuelling operation. Undercharged storage cylinders are a result of the elevated temperature which occurs in the NGV cylinder, due to compression and other processes.

There have been limited researches in the field of filling process modelling in literatures. In the first researches Kountz ${ }^{4}$ the fast refuelling process of a NGV cylinder based on the first law of thermodynamics was modelled. He developed a computer program to model a fast refuelling process for a single reservoir. Kountz et al. ${ }^{5-8}$ have also developed a CNG dispenser control program that insures integrate refuelling of NGV cylinders under a fast fill scenario. The researchers are also under way to model the fast filling of hydrogen-based fuelling infrastructure, including researches of Liss and Richards ${ }^{9}$, Liss et al. ${ }^{10}$ and Newhouse and Liss ${ }^{11}$ have studied fast filling of the hydrogen cylinder using the number of experiments. They reported a high temperature increase in the cylinder pending the process.

A few researches based on experimental studies were also carried out to study fast filling of the NGV cylinder, including the work of Thomas and Goulding ${ }^{12}$ and Shiply $^{13}$. They derived that ambient temperature variation can have an effect on the CNG fast fill process. They also concluded that the test cylinder was under-filled every time it was rapidly recharged.

Farzaneh-Gord et al. ${ }^{14-20}$ have also modelled a fast filling process. The results of these researches indicated that ambient temperature has a big effect on the filling process and final NGV cylinder conditions. Also, they ${ }^{20}$ have employed a theoretical analysis to study the effects of buffer and cascade storage bank on the performance of a CNG fuelling station.

Farzaneh-Gord et al. ${ }^{21-22}$ have also studied the effects of natural gas compositions on the fast filling process for buffer and cascade storage banks. In these researches, the conditions of the storage bank were considered constant. For studying the CNG filling process, it is vital to know the thermodynamic properties of natural gas. To compute the thermodynamic properties, the AGA8 Equation of 
State has been employed. The AGA8 equation of state has been developed by American Gas Association, especially for calculating compressibility factor and density of natural gas for custody transfer.

By employing the second law, one could calculate the amount of the entropy generation theoretically. Entropy generation is associated with thermodynamic irreversibilities, which is common in all types of thermal systems ${ }^{23-25}$. Various sources are accountable for the entropy generation. There have been numerous researches in the field of entropy generation. Generation of entropy destroys the available work of a system. Therefore, it makes good engineering sense to focus on irreversibilities ${ }^{23-25}$ of heat transfer and fluid flow processes and try to understand the function of related entropy generation mechanisms. Since then, a lot of investigations have been carried out to compute the entropy generation and irreversibility profiles for different geometric configurations, flow situations, and thermal boundary conditions. Therefore entropy minimization has been employed as a tool to determine the amount of work destruction during filling process. Based on entropy generation, Farzaneh-Gord et al. ${ }^{22,25}$ have considered the effects of the pressure level of the low and medium-pressure storage banks on CNG and Hydrogen stations performance. For CNG station, the research $^{22}$ indicates that the minimum entropy generation occurs at the pressure values of 45 bar and 123 bar for Low and Medium pressure storage bank. So the optimum pressures in Low and Medium storage banks based on entropy generation minimization were determined $P_{(L S B)}$ $o_{\text {opt }}=45 \mathrm{bar}$ and $P_{(M S B) O p t}=123 \mathrm{bar}$ respectively.

In all the above studies, the cascade storage conditions are assumed unchanged. In this work, the goal is to study the effects of varying cascade storage bank conditions on NGV cylinder filling process. A theoretical model based on mass balance and thermodynamic laws is developed and presented. Firstly, the effect of initial low, medium and high storage bank pressures on the volumes that needed for bringing up the NGV cylinder to its target pressure (200 bar) will be studied. The mass flows, thermodynamic properties and entropy generation in the cylinder and cascade storage bank are calculated during the filling process. Also, the effects of ambient (initial) temperature on important parameters of filling process are investigated.

\section{NATURAL GAS REFUELING STATION}

Figure 1 shows a typical CNG filling station. Natural gas from the distribution pipeline, usually "low" pressure at ( $<4$ bar) or possibly "medium" pressure (16 bar), is compressed using a large multi-stage compressor into a storage bank. This system is maintained at a pressure higher than that in the vehicle's on-board storage so that gas flows to the vehicle under differential pressures. Typically, the high pressure of storage bank will operate in the range of 205 bar to 250 bar, while the vehicle's maximum on-board cylinder pressure is 200 bar. In order to make the utilization of the compressor and buffer storage more efficient, fast fill CNG stations usually operate using a three-stage "cascade" storage bank. In this storage system, reservoir cylinders are put into an order of ascending pressure. During fast filling, the on-board cylinder is first connected to the low-pressure storage bank. As the flow rate reaches a pre-set level the system is first switched to the medium pressure storage bank, and then to the high-pressure storage bank to complete the fill. However, in refilling the station reservoirs the compressor is automatically switched on to fill the high pressure storage bank first, and then switches to the medium and the low pressure storage bank. This ensures that the high pressure storage bank is maintained at maximum pressure all the time, ensuring that vehicles are always supplied with the maximum amount of gas available.

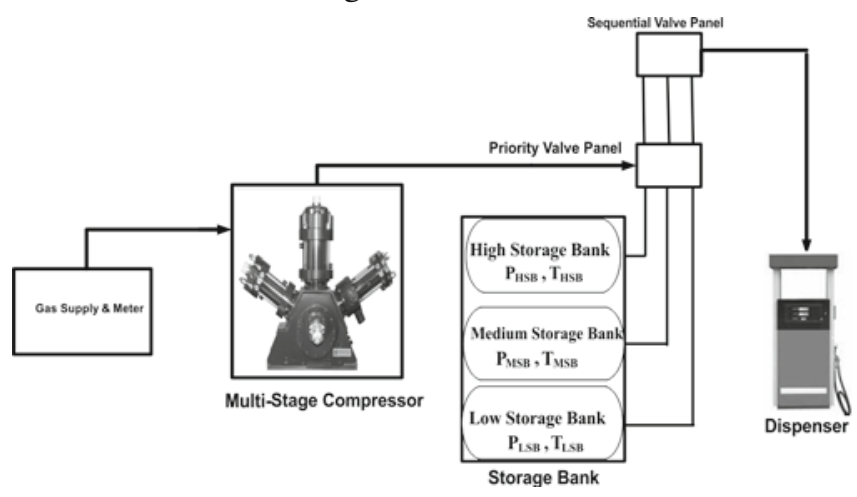

Figure 1. A schematic diagram of NGV refueling station

\section{DEFINITION OF DIMENSIONLESS PARAMETERS}

In the NGV filling process, the pressures of cascade storage bank play important roles in the filling process. Typically, the pressure in a high pressure storage bank $\left(\mathrm{P}_{\mathrm{HSB}}\right)$ is in the range of 205 bar to $250 \mathrm{bar}$, while the vehicle's maximum NGV cylinder pressure is 200 bar. In other words, the target pressure $\left(\mathrm{P}_{\mathrm{T}}\right)$ in the fuelling process is 200 bar. As previously mentioned, in CNG station, the optimum pressures in Low and Medium storage banks based on entropy generation minimization are found as $P_{(L S B) O p t}=45$ bar and $P_{(M S B) O p t}=123$ bar respectively ${ }^{22}$.

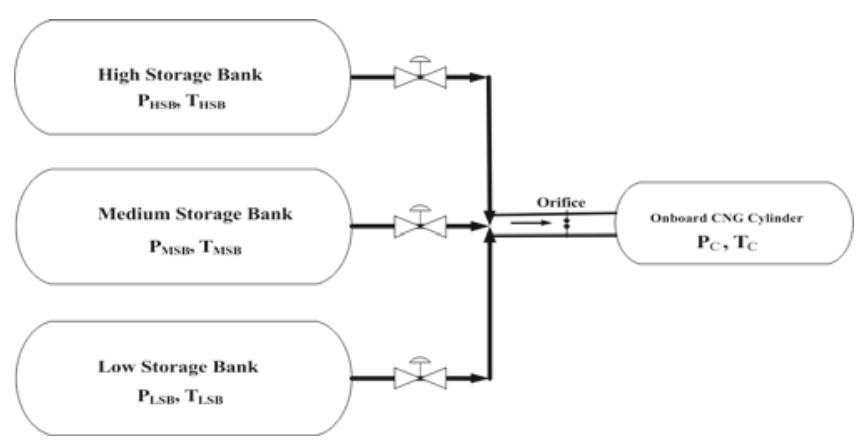

Figure 2. A schematic diagram of cascade Storage Bank

The first dimensionless number that was introduced in this study is $R P$ which is the ratio of the pressures of low $\left(\mathrm{P}_{\mathrm{LSB}}\right)$ and medium $\left(\mathrm{P}_{\mathrm{MSB}}\right)$ storage bank pressures to optimum values of Low and Medium storage bank pressures. The $R P$ for High pressure storage bank defined as the ratio of high storage bank pressure $\left(\mathrm{P}_{\mathrm{HSB}}\right)$ to target pressure $\left(\mathrm{P}_{\mathrm{T}}\right)$. Therefore the $R P$ defined as follows:

$R P=\frac{P_{L S B}}{P_{(L S B) O p t}}=\frac{P_{M S B}}{P_{(M S B) O p t}}=\frac{P_{H S B}}{P_{\mathrm{T}}}$

The next dimensionless numbers introduced in this section are $R V 1, R V 2$ and $R V 3$ that are the ratio of low 
$\left(\mathrm{V}_{\mathrm{LSB}}\right)$, medium $\left(\mathrm{V}_{\mathrm{MSB}}\right)$ and high $\left(\mathrm{V}_{\mathrm{HSB}}\right)$ storage bank volumes to $\mathrm{NGV}$ cylinder volume $\left(\mathrm{V}_{\mathrm{C}}\right)$ and defined as follows:

$$
\begin{aligned}
& R V 1=\frac{V_{L S B}}{V_{C}} \\
& R V 2=\frac{V_{M S B}}{V_{C}} \\
& R V 3=\frac{V_{H S B}}{V_{C}}
\end{aligned}
$$

\section{THERMODYNAMIC MODEL}

\section{Energy balance}

To model the fast filling process and develop a mathematical method, the NGV cylinder or the storage bank is considered as a thermodynamics open system which goes through a quasi-steady process.

To develop a theoretical model, the conservation of mass and first law of thermodynamics have been applied to the control volume (storage bank or NGV cylinder), to find two thermodynamics properties. Considering the NGV cylinder or storage bank as a control volume, the conservation of mass (continuity) equation may be written as follows:

$$
\begin{array}{ll}
\frac{d m_{C}}{d t}=\dot{m}_{i} & \text { For NGV Cylinder } \\
\frac{d m_{S B}}{d t}=\dot{m}_{e} & \text { For Storage Bank }
\end{array}
$$

In equation (5), $\dot{m}_{i}$ is the inlet mass flow rate in NGV cylinder and $\dot{m}_{e}$ is the outlet mass flow rate of storage bank. Also $m_{C}$ and $m_{S B}$ are in-Cylinder and in-Storage Bank masses of flow. It is important that the inlet mass flow rate of NGV cylinder, $\dot{m}_{i}$, is equal with the outlet mass flow rate of storage bank, $\dot{m}_{e}$ as follows:

$\dot{m}=\dot{m}_{i}=\dot{m}_{e}$

The value of $\dot{m}$ can be obtained by considering an isentropic expansion through an orifice. Applying gas dynamics laws:

$\dot{m}=C_{d} \rho_{S} A_{\text {orifice }}\left(\frac{P_{C}}{P_{S B}}\right)^{\frac{1}{\gamma}}\left\{\left(\frac{2 \gamma}{\gamma-1}\right)\left(\frac{P_{S B}}{\rho_{S B}}\right) 1\left[-\left(\frac{P_{C}}{P_{S B}}\right)^{\frac{\gamma-1}{\gamma}}\right]\right\}^{\frac{1}{2}}$

if $\frac{P_{C}}{P_{S B}} \leq\left(\frac{2}{\gamma+1}\right)^{\frac{\gamma}{\gamma-1}}$

$\dot{m}=C_{d} \sqrt{\gamma P_{S B} \rho_{S B}} A_{\text {orifice }}\left(\frac{2}{\gamma+1}\right)^{\frac{\gamma+1}{2(\gamma-1)}}$

if $\frac{P_{C}}{P_{S}}>\left(\frac{2}{\gamma+1}\right)^{\frac{\gamma}{\gamma-1}}$

In equations (7), (8) $C_{d}$ is discharge coefficient of the orifice.

The first laws of thermodynamics for a control volume a general form can be written as follows:

$\dot{Q}_{c v}+\sum \dot{m}_{i}\left(h_{i}+V_{i}^{2} / 2+g z_{i}\right)=\sum \dot{m}_{e}\left(h_{e}+V_{e}^{2} / 2+g z_{e}\right)+$

$+d / d t\left[m\left(u+V^{2} / 2+g z\right)\right]_{c v}+\dot{W}_{c v}$
The work term is zero in the filling process and the change in potential and kinetic energy can be neglected. The equation then could be simplified for NGV cylinder and storage bank as below:

$\frac{d U_{C}}{d t}=\delta \dot{Q}_{C}+\dot{m}_{i}\left(\frac{V_{i}^{2}}{2}+h_{i}\right)$ For NGV Cylinder

$\frac{d U_{S B}}{d t}=\delta \dot{Q}_{S B}-\dot{m}_{e}\left(\frac{V_{e}^{2}}{2}+h_{e}\right) \quad$ For Storage Bank

As $h_{S B}=\frac{V_{i}^{2}}{2}+h_{i}=\frac{V_{e}^{2}}{2}+h_{e}$ and $\dot{m}=\dot{m}_{i}=\dot{m}_{e}$ the above equation further could be simplified as:

$\frac{d U_{C V}}{d t}=\delta \dot{Q}_{C V} \pm \dot{m} h_{S B}$

In equation (11), the positive and negative signs have been used respectively for the NGV cylinder and the storage bank.

The heat lost from the NGV cylinder and storage bank to the environment could be calculated as

$\delta \dot{Q}_{C V}=-U_{H C V} A_{C V}\left(T_{C V}-T_{\infty}\right)$

$U, A, T$ and $T_{\infty}$ are respectively the overall heat transfer coefficient, surface area, in-cylinder temperature and ambient temperature, for control volume that could be the NGV cylinder or the storage bank. Combining equations (5), (11) and (12), the following equation is obtained:

$\frac{d(m u)_{C V}}{d t}=-U_{C V} A_{C V}\left(T_{C V}-T_{\infty}\right) \pm \frac{d m_{C V}}{d t} h_{S B}$

Or in the following form:

$\frac{d\left(m_{C V} u_{C V}\right)}{d t} \mp \frac{d\left(m_{C V} h_{S B}\right)}{d t}=-U_{C V} A_{C V}\left(T_{C V}-T_{\infty}\right)$

The above equation could be rearranged in the following form:

$d\left(m_{C V} u_{C V} \mp m_{C V} h_{S B}\right)=-U_{C V} A_{C V}\left(T_{C V}-T_{\infty}\right) d t$

The above equation could be integrated from the "outset" of filling, up to the "present" time as:

$\int_{0}^{p} d\left(m_{C V} u_{C V} \mp m_{C V} h_{S B}\right)=-\int_{0}^{t} U_{C V} A_{C V}\left(T_{C V}-T_{\infty}\right) d t$

The integration of the above equation for a storage bank with single the reservoir fuelling station resulted in:

$m_{p}\left(u_{p}-h_{S B}\right) \pm m_{o}\left(u_{o}-h_{S B}\right)=-U_{C V} A_{C V} \Delta T_{a v} t$

When $m_{p}, m_{o}$ are mass of charged gas at "present" and "outset" of filling process, $\Delta T_{a v}$ is average temperature difference between cylinder and environment which defined as:

$\Delta T_{a v}=\frac{1}{t} \int_{o}^{t}\left(T_{C V}-T_{\infty}\right) d t$

The first law of thermodynamic for the NGV cylinder or storage bank finally could be written as:

$u_{p}=h_{S B}-U_{p} A_{C V} \Delta T_{a v} t \pm \frac{m_{o}}{m_{p}}\left(u_{o}-h_{S B}\right)$

The equations (7), (8) and (19) could be employed to obtain the two thermodynamic properties of the in-cylinder or storage bank natural gas at any time. For an adiabatic system, equation (19) could be more simplified as: 
$u_{p}=h_{S B} \pm \frac{m_{o}}{m_{p}}\left(u_{o}-h_{S B}\right)$

Note that in equation (20), the control volume could be used for the NGV cylinder or storage bank. Also the positive and negative signs have been used respectively for the NGV cylinder and the storage bank.

By knowing two independent thermodynamics properties (here specific internal energy and specific volume), the other in-cylinder and in-storage bank properties could be found.

\section{Entropy generation model}

The second law of thermodynamic and flow processes occurring in the storage bank of the CNG filling station, adopted in this study, makes it possible to evaluate the entropy generation rate, $\dot{S}_{g e n}$, for the characteristic nodes of the system.

The second law of thermodynamic for filling process of a NGV cylinder and storage bank could be presented as:

$\dot{S}_{g e n, C}=d S_{C} / d t-\delta \dot{Q}_{C} / T_{\infty}-\dot{m}_{i} s_{i} \geq 0 \quad$ For NGV Cylinder

$\dot{S}_{g e n, S}=d S_{S B} / d t-\delta \dot{Q}_{S B} / T_{\infty}+\dot{m}_{e} s_{e} \geq 0$ For Storage Bank

Here, all irreversibility assumed to have occurred from the inlet to the in-cylinder position. This makes an isentropic expansion from reservoir to inlet position, which means $s_{i}=s_{e}=s$. Considering this assumption and this verity that $\dot{m}=\dot{m}_{i}=\dot{m}_{e}$ and also combining equations (5), (12) and (21), the following equation could be obtained:

$\dot{S}_{g e n, C}=\frac{d\left(m_{C} s_{C}\right)}{d t}-\frac{d m}{d t} s+U_{H C} A_{C}\left(T_{C}-T_{\infty}\right) / T_{\infty}$ For NGV Cylinder

$\dot{S}_{g e n, S B}=\frac{d\left(m_{S B} s_{S B}\right)}{d t}+\frac{d m}{d t} s+U_{H S B} A_{S B}\left(T_{S B}-T_{\infty}\right) / T_{\infty}$ For Storage Bank

The total entropy generation could be obtained as the summation of entropy generation of the NGV cylinder $\dot{S}_{g e n, C}$ and the storage bank $\dot{S}_{g e n, S B}$ as below:

$\dot{S}_{\text {tot }}=\dot{S}_{g e n, C}+\dot{S}_{g e n, S B}$

The above equation could be rewritten as:

$\dot{S}_{\text {tot }}=\frac{d\left(m_{C} s_{C}\right)}{d t}+U_{H C} A_{C}\left(T_{C}-T_{\infty}\right) / T_{\infty}+\frac{d\left(m_{S B} s_{S B}\right)}{d t}+$

$+U_{H S B} A_{S B}\left(T_{S B}-T_{\infty}\right) / T_{\infty}$

Equation (24) could be more simplified for an adiabatic system as:

$\dot{S}_{t o t}=\frac{d\left(m_{C} s_{C}\right)}{d t}+\frac{d\left(m_{S B} s_{S B}\right)}{d t}$

Or in the following form:

$\dot{S}_{t o t} d t=d\left(m_{C} s_{C}-m_{C} s\right)+d\left(m_{S B} s_{S B}+m_{S B} s\right)$

The above equation can be integrated from the "start" of the filling to the "present" time as:

$S_{\text {tot }}=\int_{s}^{p} d\left(m_{C} s_{C}-m_{C} s\right) d t+\int_{s}^{p} d\left(m_{S B} s_{S B}+m_{S B} s\right) d t$

For a fuelling station with a single reservoir in which $s_{R}$ remains constant throughout the filling process, the integration of the above equation resulted to a simple equation as:

$S_{\text {tot }}=m_{C}\left(s_{C}-s\right)-m_{C S}\left(s_{C s}-s\right)+m_{S B}\left(s_{S B}-s\right)-$

\section{The numerical procedure}

The procedure for calculating the in-cylinder and in-storage bank conditions of CNG start from the initial conditions. Equation (6) (or (7)) is employed to calculate the inlet mass flow rate. Equation 5 is then utilized to compute the in-cylinder and in-storage bank masses and consequently specific volume of CNG within the cylinder and storage bank using first order Euler numerical scheme. Similarly, equation (20) is solved to calculate the in-cylinder specific internal energy of methane at the new time step. Upon determination of two independent thermodynamic properties (here specific internal energy and specific volume), other properties can be easily found from the methane property tables.

\section{RESULTS AND DISCUSSION}

The orifice diameter and the NGV cylinder volume were considered to be $1 \mathrm{~mm}$ and 67 litters respectively. Because methane is occupied the large percentage (between 70 to $99 \%$ ) of the natural gas, for the sake of simplicity it is assumed that methane is the only substance in the Natural gas and thermodynamic properties table has been employed.

In the $\mathrm{CNG}$ station, the filling process should be completed when the final pressure of the NGV cylinder reaches to 200 bar. To achieve this goal, the volume of the storage bank is very important. Figure 3 shows the ratio of the volumes of storage bank, RV1, RV2 and RV3, which required for bringing up the NGV cylinder to its target pressure for various RP numbers. As shown in this Figure, for bringing up the NGV cylinder to its target pressure, the various RV numbers should be selected. In Figure 3, the initial pressure of storage bank have varied from $\mathrm{RP}=1.025, \mathrm{RP}=1.05$ and $\mathrm{RP}=1.1$. As is clear, the initial pressure of storage bank has a big effect on the necessary storage bank volume for bringing up the NGV cylinder to its target pressure. As the minimum initial pressure in storage bank is a critical condition for filling process, the results have been presented here for RP equal 1.025. So the low, medium and high pressures in the storage bank are selected 46.2275 bar, 126.075 bar and 205 bar respectively. With selecting these pressures for completing the refuelling process, the volume of low, medium and high storage bank should be selected respectively 14, 4 and 2 times than the NGV cylinder volume.

Figure 4 shows the time required for filling CNG cylinder during filling process for various RP numbers while initial (ambient) conditions kept constant at $300 \mathrm{~K}$ and

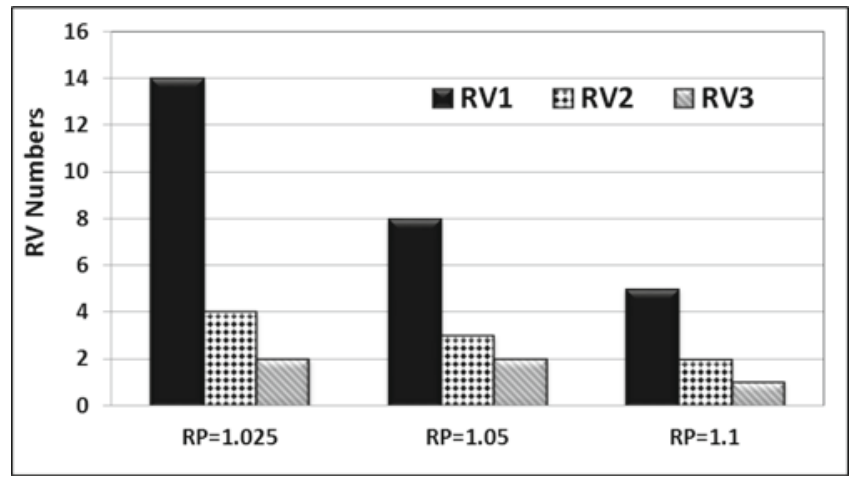

Figure 3. Effect of RP numbers on RV numbers 


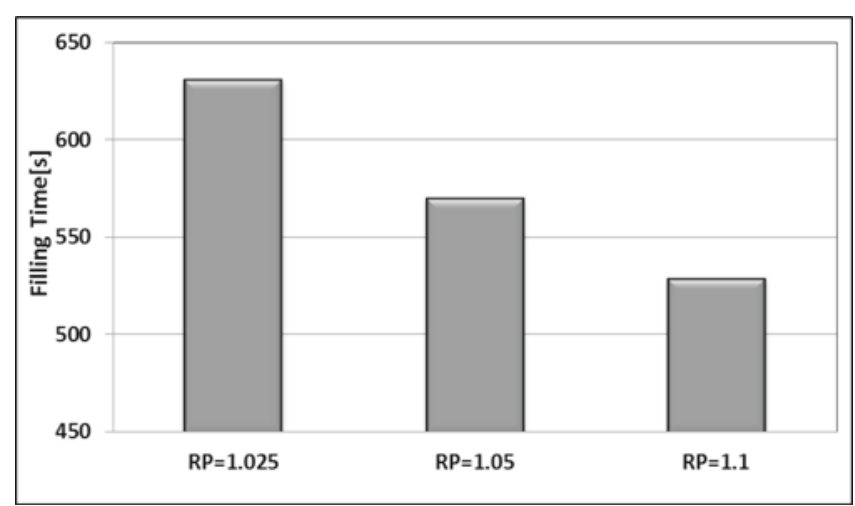

Figure 4. Filling time for various RP numbers

1 bar. According to Figure 4, whatever the RP number increases, the filling time reduces.

Figure 5 shows mass flow rate profiles that exit from the storage bank and enter into the NGV cylinder during the filling process for various RP numbers. According to Figure 5, in the early part of filling, the mass flow rates are nearly constant due to choking. Also whatever the $\mathrm{RP}$ number is greater; the mass flow rate in early part of filling is higher. Note from figure, the mass flow rate entering into NGV cylinder is equal to the mass flow rate that leaving the storage bank.

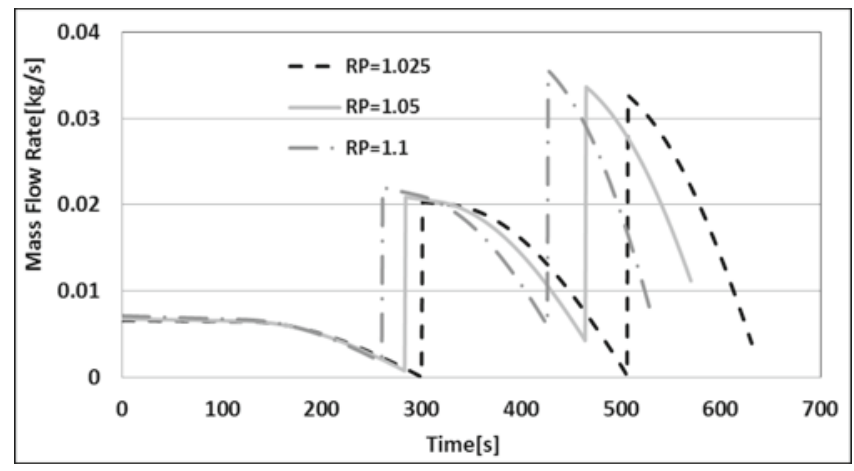

Figure 5. Mass flow rate profiles during the $\mathrm{CNG}$ filling process for various RP numbers

Figure 6 shows dynamic pressure profiles of NGV cylinder and storage bank during the filling process. Note from the figure, the time required to reach the final pressure in NGV cylinder is about 630 seconds. This value is 130 seconds higher ${ }^{22}$ than the time required when thermodynamic conditions of storage bank assumed unchanged. It should also be noted that the filling time

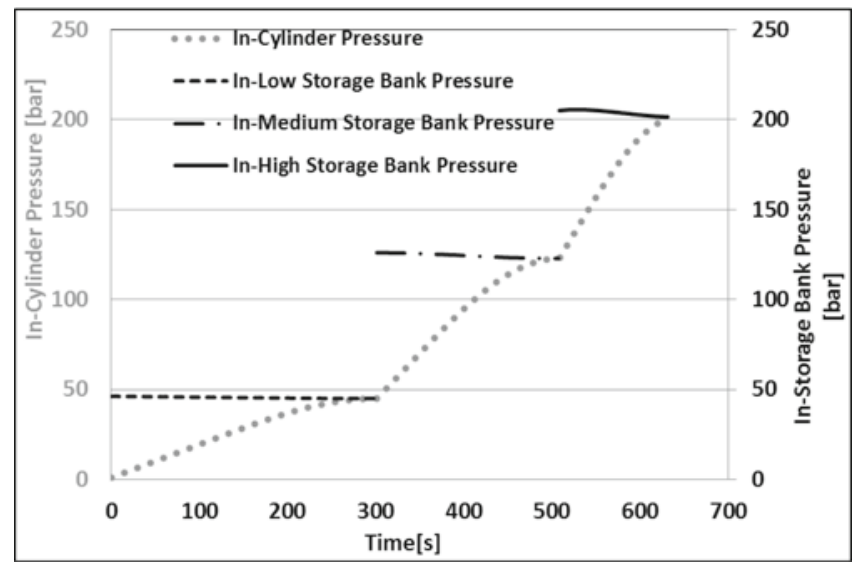

Figure 6. The NGV in-cylinder and the in-cascade storage bank pressure profiles during filling process $(\mathrm{RP}=1.025)$ could also be reduced by appropriate sizing of piping equipments (e.g. orifice diameter).

Figure 7 shows dynamic NGV in-cylinder and storage bank temperature profiles for the case where the initial temperature kept constant at $300 \mathrm{~K}$. Note from Figure 7 , the in-cylinder gas temperature falls pending the early stages of charging before rising to a final value. The proof for the dip in this curve is the consequence of the Joule-Thompson cooling effect as the gas undergoes an isenthalpic expansion through the orifice from the supply pressure to the initially low NGV cylinder pressure. Note from Figure 7, rise in temperature only occurs when the NGV cylinder is connected to the lowest pressure storage bank and temperature profile is nearly monotonic otherwise. Note, discontinuity in temperature profiles is due to switching to another storage bank. In other words, storage bank temperature near constants during the blow down $\mathrm{CNG}$ fuel of the storage bank.

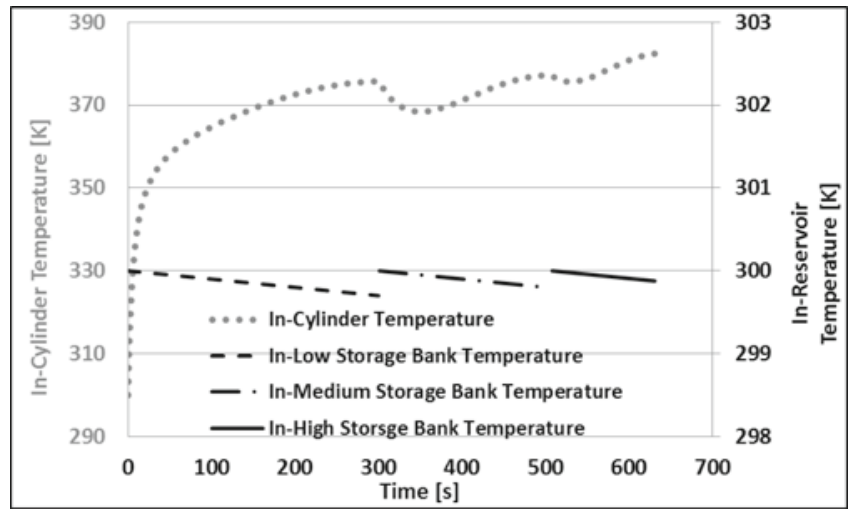

Figure 7. Temperature profiles of the NGV cylinder and cascade storage bank during the filling process $(\mathrm{RP}=1.025)$

In Figure 8, the NGV in-cylinder and in-storage bank mass variations during filling process are shown. Note from the Figure, the mass requirement of $\mathrm{CNG}$ fuel in the low, medium and high storage bank for completing the filling process is equal $30 \mathrm{~kg}, 26 \mathrm{~kg}$ and $21.5 \mathrm{~kg}$ respectively and the final in-cylinder mass is $7 \mathrm{~kg}$.

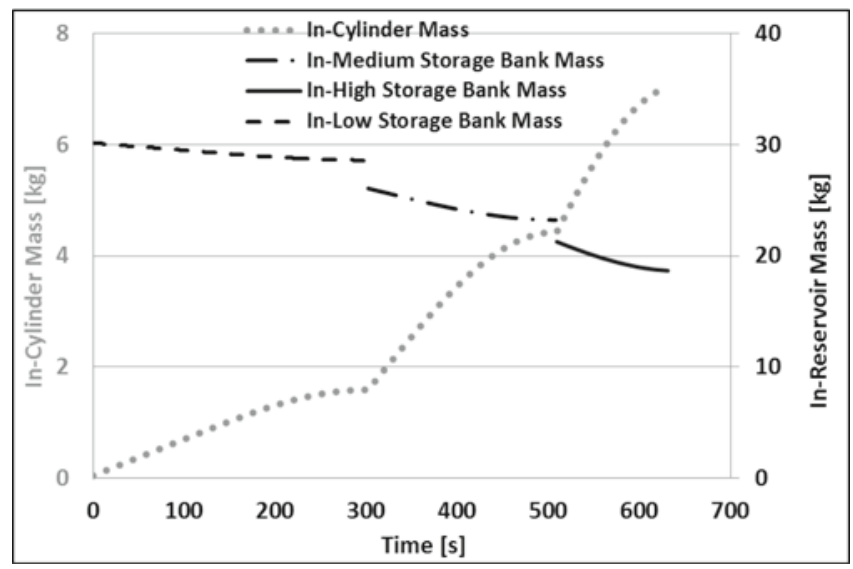

Figure 8. The NGV in-cylinder and in-cascade storage bank mass variations during filling process $(\mathrm{RP}=1.025)$

In the previous studies ${ }^{17-20}$ it was found that initials in-cylinder temperature (which could be represented by ambient temperature) has big effects on the final NGV in-cylinder and storage bank properties. Figure 9 and 10 show how the final temperature and charged mass varies with initial temperature (in the NGV cylinders 
and storage bank) which could illustrate the effect of ambient temperature. The ambient temperature has opposite effects on the final in-cylinder and storage bank temperatures and charged masses. The final in-cylinder and storage bank temperatures increase as ambient temperature increases whereas the final mass of NGV cylinder and storage bank with diminution of ambient temperature increases. The significant point is that by increasing the initial (ambient) temperature, the final in-cylinder and storage bank temperatures increase linearly. Also it can be seen as the initial temperature increases the charged mass decreases. This means that the driving range of $\mathrm{CNG}$ vehicles will decrease if filling is carried out in hot weather compared to the colder conditions.

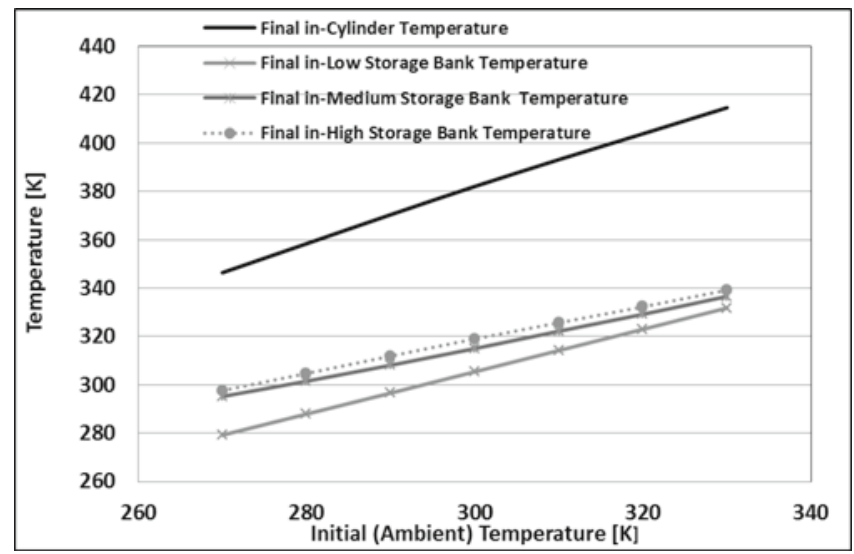

Figure 9. The effect of the initial (ambient) temperature on the final in-cylinder and cascade storage bank temperatures $(\mathrm{RP}=1.025)$

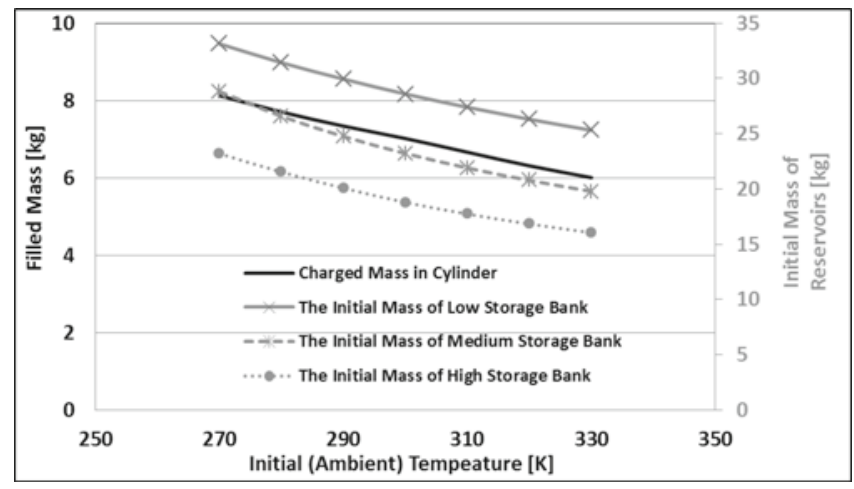

Figure 10. The effect of the initial (ambient) temperature on the final in-cylinder and the cascade storage bank temperatures $(\mathrm{RP}=1.025)$

As reminisced previously, entropy generation is dependent on thermodynamic irreversibilities. Irreversibilities destroy available work in the CNG filling station. As, the available work is provided by the compressor so one could conclude that as entropy generation is decreased, available work destruction is decreased, too.

Figure 11 shows entropy generation in the NGV cylinder, storage bank and the total entropy generation that was obtained from summation of entropy generation of NGV cylinder and storage bank for filling an empty NGV cylinder. As seen in Figure 11, the entropy generation in the storage bank is much further than entropy generation of the NGV cylinder.

Figure 12 shows the effect of initial temperature on the entropy generation of NGV cylinder, storage bank and summation of two. As in this figure, for the NGV

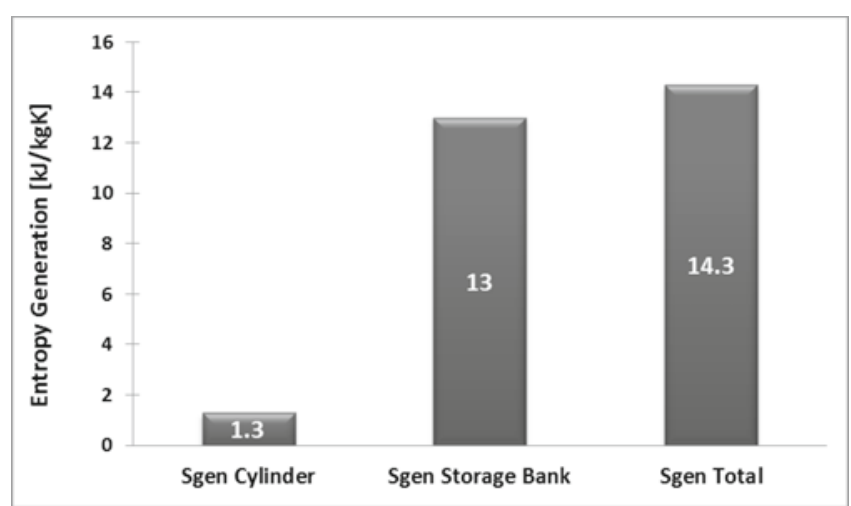

Figure 11. Entropy generation in the NGV cylinder, storage bank and summation of tow $(\mathrm{RP}=1.025)$

cylinder and the storage bank, the entropy generation at low temperatures is much higher than the high temperatures so the entropy generation in $270 \mathrm{~K}$ are respectively $3.1 \mathrm{~kJ} / \mathrm{kgK}$ and $18.7 \mathrm{~kJ} / \mathrm{kgK}$ for $\mathrm{NGV}$ cylinder and storage bank while the entropy generation at $340 \mathrm{~K}$ are respectively $0.03 \mathrm{~kJ} / \mathrm{kgK}$ and $6.6 \mathrm{~kJ} / \mathrm{kgK}$.

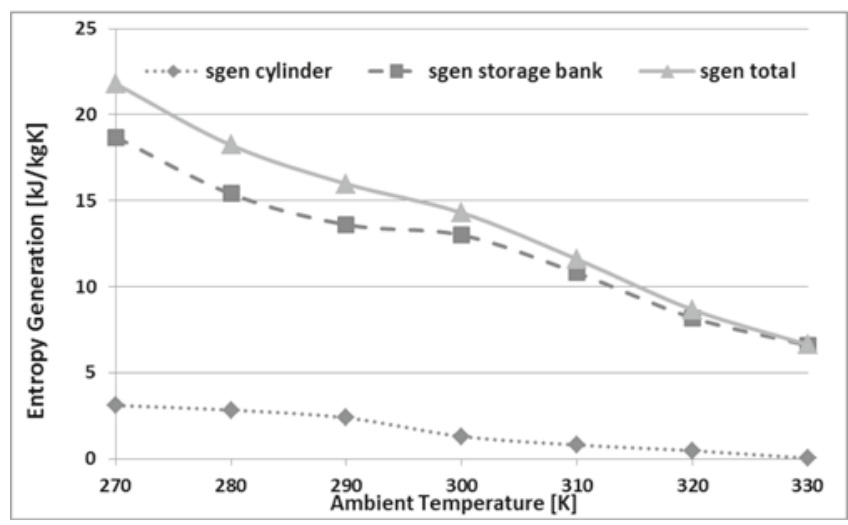

Figure 12. The effect of initial (ambient) temperature on entropy generation in the NGV cylinder, storage bank and the total summation $(\mathrm{RP}=1.025)$

\section{CONCLUSION}

The first and second laws of thermodynamics have been used as theoretical tools in order to investigate the conditions of the NGV cylinder and the cascade storage bank pending the filling process. A theoretical analysis has been built to study the blow downing cascade storage bank and filling NGV cylinder. The important parameters which were investigated are variation of the temperature, pressure, mass flow rate, charged mass and entropy generation for the NGV cylinder and the cascade storage bank. Also it is discussed how ambient temperature affects these parameters.

The result shows the initial pressure of storage bank has a big effect on the storage bank volume for bringing up the NGV cylinder to its target pressure (200 bar). The volumes of low, medium and storage bank that are required for bringing up the NGV on-board cylinder to its final pressure (200 bar) for the various initial cascade storage bank pressures, $\mathrm{RP}=1.025\left(\mathrm{P}_{\mathrm{LSB}}=46.2275\right.$ bar, $\mathrm{P}_{\mathrm{MSB}}=126.075$ bar and $\mathrm{P}_{\mathrm{LSB}}=205$ bar), $\mathrm{RP}=1.05$ $\left(\mathrm{P}_{\mathrm{LSB}}=47.355\right.$ bar, $\mathrm{P}_{\mathrm{MSB}}=129.15$ bar and $\mathrm{P}_{\mathrm{LSB}}=210$ bar $)$ and $\mathrm{RP}=1.1\left(\mathrm{P}_{\mathrm{LSB}}=49.61\right.$ bar, $\mathrm{P}_{\mathrm{MSB}}=135.3$ bar and $\mathrm{P}_{\mathrm{LSB}}=220$ bar) were found. 
For RP $=1.025$ the result also shows the filling time is about 130 seconds higher than CNG station with the reservoir system with unchanged conditions.

The results also reveal that the entropy generation during filling process in storage bank is much higher than entropy generation of the NGV cylinder.

Considering the above comments, one could conclude that the ambient temperature has big effects on the filling process, final in-cylinder and cascade storage bank conditions and should be considered as an important parameter.

\section{Nomenclature}

A Area, $\left[\mathrm{m}^{2}\right]$

$\mathrm{C}_{\mathrm{d}} \quad$ Orifice discharge coefficient,

$c_{p}, c_{v} \quad$ Constant pressure \& volume specific heats, $[\mathrm{kJ} / \mathrm{kg} \mathrm{K}]$

$g \quad$ Gravitational acceleration, $\left[\mathrm{m} / \mathrm{s}^{2}\right]$

$h \quad$ Specific enthalpy, $[\mathrm{kJ} / \mathrm{kg}]$

$\dot{m} \quad$ Mass flow rate, $[\mathrm{kg} / \mathrm{s}]$

M Molecular weight, [ $\mathrm{kg} / \mathrm{kmol}]$

$P \quad$ Pressure, [bar or Pa]

$\dot{Q} \quad$ Heat transfer rate, $[\mathrm{kW}]$

$T \quad$ Temperature, $\left[\mathrm{K}\right.$ or $\left.{ }^{\circ} \mathrm{C}\right]$

$u \quad$ Internal energy, $[\mathrm{kJ} / \mathrm{kg}]$

h Enthalpy, $[\mathrm{kJ} / \mathrm{kg}]$

s Entropy, $[\mathrm{kJ} / \mathrm{K}]$

$\mathrm{t}$ time, $[\mathrm{s}]$

$v \quad$ Specific volume, $\left[\mathrm{m}^{3} / \mathrm{kg}\right]$

$V \quad$ Volume, $\left[\mathrm{m}^{3}\right]$

$W \quad$ Actual work, $[\mathrm{kJ} / \mathrm{kg}]$

$\dot{W} \quad$ Actual work rate, [kW or MW]

$z \quad$ Height, $[\mathrm{m}]$

$Z \quad$ Compressibility factor

$\rho \quad$ Density, $\left[\mathrm{kg} / \mathrm{m}^{3}\right]$

$\gamma \quad$ Isentropic Exponent

RP Ratio of pressure

RV1 Ratio of volume for Low Storage Bank to NGV cylinder

RV2 Ratio of volume for Medium Storage Bank to NGV cylinder

RV3 Ratio of volume for High Storage Bank to NGV cylinder

\section{Subscript}

C NGV cylinder

CV Control volume

e Exit condition

i Initial or inlet condition

LSB Low Storage Bank

MSB Medium Storage Bank

HSB High Storage Bank

Opt Optimum

$\mathrm{p} \quad$ Present condition

S Start of filling process

SB Storage bank

T Target Pressure

a, $\infty$ Ambient

av Average

gen Generation

tot Total

\section{LITERATURE CITED}

1. Mansha, M., Saleemi, A.R., Javed, S.H. \& Nadeem F., (2011). Analysis of a Detailed Kinetic Model of Natural Gas Combustion in IC Engine, Pol. J. Chem. Technol., 13, 1, 6-15, DOI: $10.2478 / \mathrm{v} 10026-011-0002-0$.

2. Farzaneh-Gord, M., Rahbari, HR. \& Nikofard, H. (2012), The effect of important parameters on the natural gas vehicles driving range, Pol. J. Chem. Technol., 14, 4, 61-68. DOI: 10.2478/v10026-012-0104-3.

3. National Iran Oil Products Distribution Company website available at: WWW.NIOPC.ir

4. Kountz, K. (1994). Modelling the Fast Fill Process in Natural Gas Vehicle Storage Cylinders, American Chemical Society Paper at 207th National ACS Meeting, March.

5. Kountz, K., Kenneth, J., Blazek, C. \& Christopher, F. (1997). NGV Fuelling Station and Dispenser Control Systems, report GRI-97/0398, Gas Research Institute, Chicago, Illinois, November.

6. Kountz, K. \& Liss, W. (1998). U. S. Patent 5,752,552, May 19.

7. Kountz, K., Liss, W. \& Blazek, C. (1998). C. U.S. Patent 5,810,058, Sept. 22.

8. Kountz, K., Liss, W. \& Blazek, C. (1998). A New Natural Gas Dispenser Control System”, Paper at 1998 International Gas Research Conference, San Diego, November 3.

9. Liss, W.E. \& Richards, M. (2002). Development of a Natural Gas to Hydrogen Fuelling Station, Topical Report for U.S. DOE, GTI-02/0193, Sept.

10. Liss, W.E., Richards, M., Kountz, K. \& Kriha, K. (2003). Modelling and Testing of Fast-Fill Control Algorithms for Hydrogen Fueling, 2003 National Hydrogen Association Meeting, March.

11. Newhouse, N.L. \& Liss, W.E. (1999). Fast Filling of NGV Fuel Containers, SAE paper -01-3739.

12. Thomas, G., Goulding, J. \& Munteam, C., Measurement. (2002). Approval and Verification of CNG Dispensers, NWML KT11 Report.

13. Shipley, E., (2002), Study of natural gas vehicles (NGV) during the fast fills process, Thesis for Master of Science, College of Engineering and Mineral Resources at West Virginia University.

14. Farzaneh-Gord, M., Eftekhari, H., Hashemi, S., Magrebi, M. \& Dorafshan, M. (2007). The effect of initial conditions on filling process of $\mathrm{CNG}$ cylinders, The second International conference on Modeling, Simulation, And Applied optimization, Abu Dhabi, UAE, March 24-27.

15. Farzaneh-Gord, M. (2008). Compressed natural gas Single reservoir filling process", Gas Int. Eng. Man., 48, 6.

16. Farzaneh-Gord, M., Hashemi, SH. \& Farzaneh-Kord, A.. (2008). Thermodynamics Analysis of Cascade Reservoirs Refuelling Process of Natural Gas Vehicle Cylinders, World Appl. Sci. J., 5, 143-149.

17. Farzaneh-Gord, M., Deymi-Dashtebayaz, M. \& Rahbari, HR. (2011). Studying effects of storage types on performance of CNG refuelling stations, J. Nat. Gas. Sci. Eng., 3, 334-340. DOI: 10.1016/j.jngse.2011.02.001.

18. Farzaneh-Gord, M. \& Deymi-Dashtebayaz, M. (2013). Optimizing Natural Gas Fuelling Station Reservoirs Pressure Based on Ideal Gas Model, Pol. J. Chem. Technol., 15, 1, 88-96. DOI: 10.2478/pjct-2013-0015.

19. Farzaneh-Gord, M., Deymi-Dashtebayaz, M. \& Rahbari, HR. (2013). Studying Transmission of Fuel from storage Bank to NGV Cylinder in CNG Rapid Refuelling Station, J. Brazilian Soc. Mech. Sci. Eng. XXXIV 429-435. DOI: 10.1590/ S1678-58782012000400002.

20. Farzaneh-Gord, M., Deymi-Dashtebayaz, M. \& Rahbari, HR. (2013). Effects of Gas Types and Models on Optimized Gas Fuelling Station Reservoir's Pressure, To be Published $J$. 
Brazilian Soc. Chem. Sci. Eng. 30, 2, 399-411.DOI:10.1590/ S0104-66322013000200017.

21. Farzaneh-Gord, M., Rahbari, H.R. \& Deymi-Dashtebayaz, M. (2013). Effects of Natural Gas Compositions on CNG Rapid Refuelling Process for Buffer Storage System OGST J. DOI :10.2516/ogst/2012010.

22. Farzaneh-Gord, M., Deymi-Dashtebayaz, M. \& Rahbari, HR. (2012). Optimizing Compressed Natural Gas Refulling Stations Reservoir Pressure Based on Thermodynamic Analysis, Int. J. Exergy, 10, 3. DOI: 10.1504/IJEX.2012.046836.

23. Qin Cai, Mingwei Tong and Xiujuan Bai, (2012), Korean J. Chem. Eng., 29, 4. DOI: 10.1007/s11814-011-0197-z.

24. Bejan, A. (1996). Entropy Generation Minimization, CRC, Boca Raton, NY.

25. Farzaneh-Gord, M., Deymi-Dashtebayaz, M., Rahbari, HR. \& Niazmand, H. (2012). Effects of Storage Types and Conditions on Compressed Hydrogen Fuelling Stations Performance, Int. J. Hydrogen Energy, 37, 3500-3509. DOI: 10.1016/j. ijhydene.2011.11.017. 